\title{
Evaluation of Spatial Satisfaction in Administrative Environment of Art Galleries
}

\author{
Sheida Korjani ${ }^{1}$, Shabnam Akbari Namdar ${ }^{1}$
}

\begin{abstract}
Contemporary art galleries and museums are now facing a new market with many and varied visitors, who are differently motivated and have different expectations. In most cases, renovated historic buildings face significant challenges in provision of suitable administration layout for the staff. This study was intended to provide applicable information for design and management of effective workplaces in renovated art galleries and museums by a survey on five galleries and museums. The results revealed that renovation in the office environment of renovated historic buildings converted to galleries and museums have improved the amount of work-surface, function of furniture, amount of storage, function of storage, and style of furniture. Besides, the analysis showed that the open floor plan of a work environment in art galleries, over time, is a source of noise problems and deprives office workers of privacy and personalized area.
\end{abstract}

Keywords: building, gallery, satisfaction, sustainability.

\section{Introduction}

Most critics of museum and art gallery management systems argue that they lack customer orientation, are playgrounds of political correctness and are trapped in custodianship of ancient artifacts failing to present them in an exciting and marketable way (Dragicevica \& Letunica, 2014). Others (Boorsma, 2006) have criticized the lack of research scope for many art galleries and institutions and the lack of customer orientated interaction, especially in administrative system of art galleries due to lack of attention to workplace conditions of employees. The importance of intellectual productivity is now highly recognized in art galleries and lead art institutions to investigate elements of the work environment affecting the capabilities of workers. The work environment is like a home to workers who spend a long time there. As a result, providing a pleasant environment through adequately planned space means not only an improvement in qualitative productivity, but also an eventual improvement in the quality of life itself. It is well understood that the physical quality of the work environment has a direct effect on the health of workers and their quality of life (Sundstrom, 1991); however, organizations have not taken this point seriously. Regular appraisal of the work environment by experts benefits office design and management, and contributes to the development of positive office environments. It also provides information on how the space can function better and suggests possible areas of improvement. A pleasant environment may increase work efficiency, pride in the job and the organization. Several studies have discussed the impact of architectural space on human. The quality of the work environment and its 
role in increasing productivity must not be overlooked because of the potential benefits. The main objective of this research was to provide information on planning functional office environments in renovated historic buildings that are converted into art galleries or museums through an evaluation of renovated workspaces.

\section{Physical Environment in Art Gallery}

Most developed countries treasure their heritage and see them as having unique educational potential. In relation to this, the function of museums and art galleries in these countries has seen massive changes, from being a repository of static presentation of artefact collections into active learning environment for visitors. With vast collection of artefacts and creative planning, museums and art galleries are transformed into locations of exciting learning environments, infusing new and more meaningful learning experience. Australia, for example, has strong museum organization. Museum Victoria, for example, is the largest public museum organization in Australia. The museums and art galleries under management of Museum Victoria provide a wide range of educational materials and programs for teachers and students of all ages. Every operation is governed by a clear code of ethics (Isa \& Forrest, 2011).

Given the role of museums and art galleries is to educate, inspire and portray stories of the past, knowledge generation and stimulation, a service centric paradigm for analysis and management is argued to be more appropriate. Very often in art galleries or museums (classical and modern) visitors are guided in the manner that they only pass by the exponents and it fails to satisfy visitors adequately. Very rarely curators go one step further applying innovative and new strategies including all this elements (Dragicevica \& Letunica, 2014). These issues are sometimes considered as a weakness for administrative management of a gallery or museum and sometimes seems to be related to spatial organization of the building. In the case of art galleries and museums, like other humanities and social sciences, the knowledge obtained from pure or theoretical research, institutional research, and policy research helps create new disciplines, solve organizational operations, and plan for the economic and socio-cultural development of human settlement (Moosavi, 2017). In Iran, for example, museums and art galleries are found to be lacking in clear educational policies for the public or visitors due to lack of specific unit or department, skilled and trained staff as well as sufficient funding. Samihah et al. (2000) have further clarified that the function of these institutions are still limited to exhibiting artefacts. In their recommendations, they have suggested these establishments to assume more proactive roles and position in the society, thus assisting image transformation of becoming more competitive. What is needed is the restructuring of administrative structure and spatial configuration as well as staff in these establishments with the appointment of qualified education (Isa \& Forrest, 2011).

\section{Methodology}

Data were collected in 2017 by surveying office workers in five renovated art galleries in Tabriz, Iran. Thirty workers were selected from each gallery selected conveniently from a list of art galleries undergoing renovations in the last 10 years, 
excluded relocations to a new building or area. Then, two trained interviewers, who participated in pilot study prior to the actual survey, visited each gallery. Out of 210 responses, a total of 155 were used in the data analysis due to lack of correct information or missing answers. The questions were developed based on Becker's (1990) postoccupancy evaluation of the workplace, and some relationship questions were adopted from the research of Je and $\mathrm{Ha}$ (1996). Each characteristic of the work environment was rated from 1 (not important) to 5 (important) to measure expectation level and from 1 (dissatisfied) to 5 (satisfied) to measure current workplace conditions. At this point, a gap between expectation (importance) and actual condition (satisfaction) of workplace in art gallery was the basis for the quality measurement of the spatial elements. The difference between the ideal (importance) and the actual condition (satisfaction) was defined as a "deficit".

The respondents range in age from 22 to 58 years, with an average age of 31.4. Fortyfour percent of the respondents belonged to the age group 26-30 and 38\% to the group 31-40. Seventy-two percent of the respondents were male and $28 \%$ were female. The average number of years of education of respondents was 16; and, eighty-six percent had college degrees. Job characteristics were categorized into 3 groups: administrative work, technical, and research. Forty-six percent of the respondents held administrative jobs; $27 \%$ are in administrative; and, $28 \%$ were in the research field. The total average work experience was 4.2 years for a range of one year to 17 years. The location of workplaces ranged from the ground floor to the 3rd floor. Years of renovation ranged from 1 to 4 .

\section{Findings}

The findings on each element of the selected workplace are shown in Table 1. The mean scores of each element are presented to show the realized deficit level. One out of the 14 items, privacy, shows a full point difference between what was wanted (importance) and the actual condition (satisfaction). This result showed some improvement in the quality of personal workplace, compared to Je and Ha's (1996) study that presented over a one score difference in 12 out of 14 items. Je and Ha's (1996) study also indicated privacy as the biggest "deficit", meaning that renovation and/or remodeling have greatly reduced the difference between the ideal and actual level of satisfaction in the personal workplace. Table 1 shows the results concerning the physical environment of the common workspace. In the common workplace, 3 out of 16 elements have more than a one-point deficit. They include noise level $(\mathrm{m}=1.27)$, number of meeting spaces $(\mathrm{m}=1.24)$, and privacy of meeting spaces $(m=1.19)$. This result showed a larger improvement in common workplaces after renovation of selected art galleries. Thirteen out of 17 showed a deficit score of over one point in Je and Ha's (1996) research that included "visibility" in evaluation and that included offices regardless of renovation in sample. Relationships with others had a deficit of less than one point.

The results of the evaluation by workers are shown in Table 1 and 2 . The spatial quality of the work environment, which represents the difference between the ideal and the current condition of the workplace, was analyzed using Duncan's multiple range tests according to occupation (responsibility), and years of renovation. For an accurate comparison, participants were divided into 4 groups based on age: under 25, 26-30, 31-40, and over 40. 
Occupational classification was divided into administrative work, technical, and research. Three out of fourteen items concerning personal workplace show significant differences according to occupation while no significant difference appeared regarding common workplace and relationship with workers. Significantly different appraisal was given to color of furniture, comfort of chair, and privacy as shown in Table 1. Concerning color of furniture, the sales/service group was less satisfied than the research/design group. The administrative group complained about the discomfort level of chairs more than the technical group, and also felt the lack of privacy more strongly than the technical group. Workers in the administrative group stayed much longer in the office than the technical groups and have more occasions to feel uncomfortable.

Table 1: Evaluation by Occupational Classification

$\mathrm{n}=155$

\begin{tabular}{|c|c|c|c|c|}
\hline & Items & Administrative & Technical & Research \\
\hline \multirow{14}{*}{ Personal } & Location & 0.47 & 0.58 & 0.36 \\
\hline & Arrangement of furniture & 1.18 & 0.65 & 0.52 \\
\hline & Amount of worksurface & 0.68 & 0.75 & 0.52 \\
\hline & Function of furniture & 0.75 & 0.39 & 0.32 \\
\hline & Amount of storage for work materials & 0.83 & 1.17 & 1.04 \\
\hline & Function of storage & 0.30 & 0.48 & 0.52 \\
\hline & Display area for art materials & 0.21 & 0.67 & 0.29 \\
\hline & Style of furniture & -0.13 & 0.25 & 0.04 \\
\hline & Color of furniture & $-0.28 \mathrm{AB}$ & $0.65 \mathrm{~A}$ & $0.16 \mathrm{~B}$ \\
\hline & Comfort of furniture & $1.31 \mathrm{~A}$ & $0.35 \mathrm{~B}$ & $1.00 \mathrm{AB}$ \\
\hline & Degree of privacy & $2.00 \mathrm{~A}$ & $1.17 \mathrm{~B}$ & $1.40 \mathrm{AB}$ \\
\hline & Suitability to work & 0.87 & 1.00 & 1.04 \\
\hline & Opportunity for personalization & 0.95 & 1.35 & 0.76 \\
\hline & Image of workplace & 0.38 & 0.58 & 0.48 \\
\hline \multirow[t]{16}{*}{ Common } & Overall workplace size & 0.78 & 1.58 & 1.20 \\
\hline & Shape of workplace & 0.85 & 0.79 & 0.88 \\
\hline & Density of people & 1.32 & 0.87 & 1.00 \\
\hline & Location of workplace on the floor & 0.17 & 0.13 & -0.12 \\
\hline & Quality of lighting & 0.80 & 0.78 & 1.08 \\
\hline & Quality of air-conditioning & 0.78 & 0.87 & 1.48 \\
\hline & Color of floor covering & -0.27 & 0.00 & -0.52 \\
\hline & Color of overall furniture & -0.29 & -0.43 & 0.04 \\
\hline & Noise level at workplace & 1.63 & 1.33 & 1.12 \\
\hline & Overall image & 0.12 & -0.04 & -0.20 \\
\hline & Overall environment comfort & 0.85 & 0.87 & 0.44 \\
\hline & Number of meeting spaces & 1.24 & 1.48 & 1.52 \\
\hline & Size of meeting spaces & 1.15 & 1.43 & 1.08 \\
\hline & Privacy of meeting spaces & 1.54 & 1.30 & 0.80 \\
\hline & Location of meeting spaces & 0.66 & 0.70 & 0.64 \\
\hline & Furniture of meeting spaces & 0.05 & 0.17 & 0.44 \\
\hline \multirow[t]{4}{*}{ Relationship } & Visibility to co-workers & 0.50 & 0.83 & 0.80 \\
\hline & Relationship with higher managers & 1.27 & 1.48 & 0.84 \\
\hline & Relationship with colleagues & 0.95 & 0.78 & 0.60 \\
\hline & Relationship with workers in other departments & 0.76 & 0.65 & 0.36 \\
\hline
\end{tabular}

The work environment evaluation by years of renovation in selected art galleries was also divided into 1,2, and 4 years based on data availability. The results of the analysis showed that 9 out of 14 items in the personal workplace were significantly different at the .05 
significant level (Table 2). In general, workers in renovated gallery buildings within one year showed a significantly higher level of dissatisfaction than workers in buildings renovated 24 years earlier. Respondents in one-year-old renovated gallery buildings felt significantly less satisfied with the arrangement of furniture, degree of privacy, workstation suitability, and overall personal space than respondents in 2-year-old renovated buildings.

Concerning the amount of work-surface and function of furniture, the group in oneyear-old renovated buildings felt significantly less content than those 2-year-old and 4year-old renovations. However, concerning the function of storage and the amount of storage, the group in one-year-old renovated galleries felt a significantly higher deficit than those in buildings renovated within four years. However, concerning style of furniture, the latter group felt less satisfied than the former. The result was consistent with several previous studies, which have shown that workspace adjustability and storage contribute directly to satisfaction and worker performance.

Table 2: Evaluation by Years after Renovation $\mathrm{n}=155$

\begin{tabular}{|c|c|c|c|c|}
\hline & Items & 1 & 2 & 4 \\
\hline \multirow[t]{14}{*}{ Personal } & Location & 0.61 & 0.18 & 0.54 \\
\hline & Arrangement of furniture & $1.13 \mathrm{~A}$ & $0.24 \mathrm{~B}$ & $0.83 \mathrm{~A}$ \\
\hline & Amount of worksurface & $1.19 \mathrm{~A}$ & $0.35 \mathrm{~B}$ & $0.06 \mathrm{~B}$ \\
\hline & Function of furniture & $0.94 \mathrm{~A}$ & $0.24 \mathrm{~B}$ & $0.17 \mathrm{~B}$ \\
\hline & Amount of storage for work materials & $1.37 \mathrm{~A}$ & $0.88 \mathrm{AB}$ & $0.49 \mathrm{~B}$ \\
\hline & Function of storage & $0.69 \mathrm{~A}$ & $0.45 \mathrm{AB}$ & $-0.14 \mathrm{~B}$ \\
\hline & Display area for art materials & 0.48 & 0.27 & 0.29 \\
\hline & Style of furniture & $-0.07 \mathrm{~A}$ & $-0.20 \mathrm{~A}$ & $0.44 \mathrm{~B}$ \\
\hline & Color of furniture & -0.28 & -0.22 & 0.14 \\
\hline & Comfort of furniture & 0.89 & 0.65 & 1.00 \\
\hline & Degree of privacy & $1.74 \mathrm{~A}$ & $0.96 \mathrm{~B}$ & $1.74 \mathrm{~A}$ \\
\hline & Suitability to work & $1.38 \mathrm{~A}$ & $0.34 \mathrm{~B}$ & $0.88 \mathrm{AB}$ \\
\hline & Opportunity for personalization & 1.15 & 0.75 & 0.97 \\
\hline & Image of workplace & 0.64 & 0.45 & 0.42 \\
\hline \multirow[t]{16}{*}{ Common } & Overall workplace size & $1.15 \mathrm{~A}$ & $0.58 \mathrm{~B}$ & $1.31 \mathrm{~A}$ \\
\hline & Shape of workplace & $0.87 \mathrm{AB}$ & $0.60 \mathrm{~A}$ & $0.23 \mathrm{~B}$ \\
\hline & Density of people & 1.11 & 0.67 & 1.23 \\
\hline & Location of workplace on the floor & 0.19 & -0.05 & -0.09 \\
\hline & Quality of lighting & 1.02 & 0.58 & 0.83 \\
\hline & Quality of air-conditioning & $0.91 \mathrm{AB}$ & $0.98 \mathrm{~A}$ & $0.23 \mathrm{~B}$ \\
\hline & Color of floor covering & -0.15 & -0.18 & -0.60 \\
\hline & Color of overall furniture & 0.19 & -0.13 & -0.31 \\
\hline & Noise level at workplace & 1.46 & 1.11 & 1.25 \\
\hline & Overall image & $0.37 \mathrm{~A}$ & $-0.07 \mathrm{~B}$ & $-0.06 \mathrm{AB}$ \\
\hline & Overall environment comfort & $0.92 \mathrm{~A}$ & $0.48 \mathrm{~B}$ & $0.89 \mathrm{AB}$ \\
\hline & Number of meeting spaces & 1.48 & 1.16 & 1.00 \\
\hline & Size of meeting spaces & $1.26 \mathrm{~A}$ & $0.56 \mathrm{~B}$ & $1.20 \mathrm{~A}$ \\
\hline & Privacy of meeting spaces & 1.41 & 0.93 & 1.29 \\
\hline & Location of meeting spaces & $0.94 \mathrm{~A}$ & $0.41 \mathrm{~B}$ & $0.82 \mathrm{AB}$ \\
\hline & Furniture of meeting spaces & 0.52 & 0.05 & 0.29 \\
\hline \multirow[t]{4}{*}{ Relationship } & Visibility to co-workers & $0.94 \mathrm{~A}$ & $0.33 \mathrm{~B}$ & $0.88 \mathrm{AB}$ \\
\hline & Relationship with higher officers & $1.46 \mathrm{~A}$ & $0.35 \mathrm{~B}$ & $1.14 \mathrm{~A}$ \\
\hline & Relationship with colleagues & $0.98 \mathrm{~A}$ & $0.32 \mathrm{~B}$ & $0.51 \mathrm{~B}$ \\
\hline & Relationship with workers in other departments & 0.72 & 0.33 & 0.57 \\
\hline
\end{tabular}


The evaluation of common workplace by years of renovation showed significant difference in 8 out of 16 items. The group in 2 -year old renovations felt significantly more satisfied with overall workplace size, and the size of meeting space than the oneyear and 4-year-old renovation groups. The deficit in shape of workplace was higher in the 4-year-old renovation group than in the 2-year-old renovation group. Concerning the quality of air, the latter group was less satisfied than the 4-year-old renovation group. Deficits in overall image, overall environmental comfort, location of meeting space, and visibility of co-workers was higher for the group in buildings most recently renovated when compared with workers in buildings renovated within 2 years. Workers in the 2year-old renovation group had a better relationship with senior management than others, while workers in the one-year-old renovation group had more problems with their coworkers than the 2-year and the 4-year renovation groups. Workers in the one-year-old renovated environment expressed less satisfaction with the workplace and relationships, while workers in the 2-year-old renovation environment showed higher satisfaction than the others do.

The over 40-age group felt less of a deficit than the other age groups. Administrative workers felt more dissatisfaction concerning comfort of chairs and degree of privacy than the technical group. This means that workers spending more time in the office need more consideration regarding the comfort of personal space. Results showing that workers in the most recently renovated buildings felt more deficits than other groups indicate that workers need time to adjust to their new environment. Groups in buildings renovated within 2 years were generally more satisfied than the other groups. The effect of years since renovation was apparently affected by the quality of the renovations. Attachment to the workplace increased when workers were accustomed to the environment regardless of the condition of the physical setting of the workplace.

\section{Conclusion}

The results of this survey revealed that renovation and/or remodeling of the historic buildings in order to convert to art gallery or museum, whether it is personal or public, reduces the deficit between the ideal and actual conditions. Due to the findings of the survey, privacy appeared as a deficit in the personal environment; while noise, lack of meeting space and privacy were deficits in common workplaces, and less consideration was given to meeting spaces. Generally, renovation has improved the quality of the furniture but the overall quality of the renovation has not yet reached the expectation of most workers. Newly renovated environments also gave some discomfort to the administrative workers. This means they need time to adjust themselves to the new work environment. Tension with other workers was also increased in newly improved environments. This means that like in the home, attachment to the workplace improves with the passage of time regardless of the spatial quality of the physical environment.

The trend in the work environment in art galleries and museums is moving towards a reduced office with shared work and limited workspaces; yet workers still feel higher satisfaction with more workspace. The design of the workplace and workstation in artrelated environments should be based on the work performed; however, the survey showed that the same layout and the same sizes were generally used regardless of task. 
Art galleries need to base their workplace design policy on the nature of work performed. Workstations are configured to accommodate differences in office size and support status distinctions among workers. They are not configured to encourage or enhance the ability to perform task requirements. The present study was not the whole approach, and a triangulation method would be more appropriate. Further research should extend the scope to the audit of physical quality of administrative environment and behavioral ratings as a complement to experiential measures. Other factors, which could be more influential to worker satisfaction, should be included in future research.

\section{References}

Altman. I., \& Low, S. (1992). Human behavior and environments: Advances in theory and research. (V. 12), Place attachment. Plenum Press: New York.

Becker, F. (1990). The Total Workplace: Facilities Management and the Elastic Organization. New York: Van Nostrand Reinhold.

Boorsma, M. (2006). A strategic logic for arts marketing. International Journal of Cultural Policy, 12 (1), 73-92.

Dragicevica, M., \& Letunica, S. (2014). Should museums and art galleries be just "for arts' sake" or should they suit the needs of tourists? Procedia - Economics and Finance, 15 (2014), 1197 - 1200.

Je, H. \& Ha, M. (1996). A study on the evaluation of personal and common work environment of officesbased on the survey of office workers in Seoul. Korean Institute of Interior Design Journal, No. 7, 3-12.

Isa, B., \& Forrest, D. (2011). A qualitative case study of the implementation of education programs at the National Gallery of Victoria (NGV), Australia. Procedia - Social and Behavioral Sciences, 29 (2011), $1905-1913$.

Moosavi, M. S. (2017). Emerging Opportunities of Humanities Research in Information Age. Iranian Online Journal of Interdisciplinary Humanities Research, 1(1), 1-5.

Samihah Kh. et al. (2000). Research Report on Malaysian Museum, Art Gallery \& Archives (Trans) Unpublished Report Ministry of Arts, Culture and Tourism of Malaysia.

Sundstrom, E. (1991). Work environments: Offices and factories. In D. Stokol \& I. Altman (Eds.), Handbook of Environmental Psychology (733-758). Malabar, FL: Krieger Publishing Co.

Stedman, R. C. (2003). Is it really just a social construction? The contribution of the physical environment to sense of place. Society \& Natural Resources, 16, 671-685. 